\title{
GÊNERO, SEXUALIDADE E DIREITOS DAS MULHERES: UMA PERSPECTIVA FEMINISTA ISLÂMICA ACERCA DAS LEIS DE FAMÍLIA MUÇULMANAS
}

\author{
Flávia Abud Luz*
}

\section{RESUMO}

As leis de família muçulmanas, que lidam com aspectos como o casamento, e o divórcio, refletem normas sociais, culturais e religiosas dos papeis de gênero nas sociedades em que são inseridas. Objetiva-se neste artigo apresentar e discutir os principais aspectos da intersecção entre gênero, sexualidade e Islã refletidos nas referidas leis, bem como a crítica feminista islâmica (construção discursiva que ampliou sua influência no Oriente Médio e Norte da África a partir de 1990) aos discursos que legitimam práticas normativas para expressão da sexualidade. Ao observar os princípios que estruturam as leis de família muçulmanas é possível argumentar que existe um descompasso entre os de direitos das mulheres e os discursos religiosos que legitimam práticas normativas acerca do corpo feminino.

Palavras-chave: Leis de família; crítica feminista islâmica; direitos das mulheres.

\section{GENDER, SEXUALITY, WOMEN'S RIGHTS: AN ISLAMIC FEMINIST PERSPECTIVE ON MUSLIM FAMILY LAWS}

\section{ABSTRACT}

Muslim family laws, which deal with aspects such as marriage and divorce, reflect social, cultural and religious norms of gender roles in the societies in which they are inserted. This article aims to present and discuss the main aspects of the intersection between gender, sexuality and Islam reflected in these laws, as well as the Islamic feminist critique (a discursive construction that expanded its influence in

* Doutoranda em Ciências Humanas e Sociais pela Universidade Federal do ABC (UFABC). Mestre em Ciências da Religião na Universidade Presbiteriana Mackenzie (UPM), possui especialização em Política e Relações Internacionais pela Fundação Escola de Sociologia e Política de São Paulo (FESPSP) e Bacharel em Relações Internacionais pela Fundação Armando Álvares Penteado (2014). 
the Middle East and North Africa from 1990's) to the discourses that legitimize normative practices for expression of sexuality. Looking at the principles that structure Muslim family laws, it can be argued that there is a mismatch between women's rights and religious discourses that legitimize normative practices about the female body. Keywords: Family laws; Islamic feminist criticism; women's rights.

\section{GÉNERO, SEXUALIDAD Y DERECHOS DE LAS MUJERES: UNA PERS- PECTIVA FEMINISTA ISLÁMICA SOBRE LAS LEYES FAMILIARES MUÇULMANAS}

\section{RESUMEN}

Las leyes familiares musulmanas, que abordan aspectos como matrimonio y divorcio, reflejan las normas sociales, culturales y religiosas de los roles de género en las sociedades en que se insertan. Este artículo tiene como objetivo presentar y discutir los principales aspectos de la intersección entre género, sexualidad y Islam reflejados en estas leyes, así como la crítica feminista islámica (construcción discursiva que expandió su influencia en Medio Oriente y África del Norte desde 1990) a los discursos que legitiman prácticas normativas de expresión de sexualidad. Al observar los principios que estructuran las leyes familiares musulmanas, se puede argumentar que existe un desajuste entre los derechos de las mujeres y los discursos religiosos que legitiman prácticas normativas sobre el cuerpo femenino.

Palabras clave: Leyes familiares; crítica feminista islámica; derechos de las mujeres.

\section{INTRODUÇÃO}

A consciência a respeito da desigualdade na relação entre homens e mulheres em algumas sociedades muçulmanas antecede o contato de parcelas das referidas sociedades com o denominado feminismo ocidental, conforme analisa Mojab (2001, p. 125-127), porém passa a ter maior envergadura no final do século XIX, agora com a influência do colonialismo europeu junto às elites das sociedades e em países como o Egito. As discussões acerca da compatibilidade (ou não) da emancipação feminina e da igualdade entre homens e mulheres com os princípios do Islã foram constantes no Egito, por exemplo, entre reformistas islâmicos, juristas, clérigos e parcelas da população, sendo 
que o questionamento acerca do papel inibidor do Islã frente ao surgimento de um discurso revisionista de gênero esteve presente e foi articulado por forças nacionalistas, seculares e religiosas para compor seus argumentos (Margot BADRAN, 2009).

Nas últimas décadas do século XIX e início do século XX diversos países na região do Oriente Médio e Norte da África que se encontravam sob influência colonial de potências europeias buscaram realizar reformas em seu sistema jurídico. Alguns aspectos das reformas desenvolvidas conduziram a uma espécie de secularização das leis de forma seletiva, um processo entendido para as discussões deste artigo como aquele em que os valores religiosos foram retirados da esfera pública ${ }^{1}$ e passaram a integrar de maneira mais direta o âmbito privado, como nas disposições das leis de família (John L. ESPOSITO, 2004).

Observa-se, desta forma, que as Leis de Família, um conjunto de leis que regem aspectos da vida cotidiana e privada dos crentes muçulmanos, tais como a contração do casamento, o direito ao pedido de divórcio, a custódia dos filhos gerados no casamento (também denominadas Código de Status Pessoal), permaneceram sob a influência da religião islâmica e do componente cultural de cada país, tendo em vista as disparidades entre a população do campo e da cidade, bem como outras diferenças de natureza étnica. Cabe ressaltar que as leis de família muçulmanas influenciam praticamente todos os países de população muçulmana, mesmo em Estados seculares ou que não são predominantemente muçulmanos,

\footnotetext{
A noção de secularização é derivada da influência europeia junto aos países da região do Oriente Médio e Norte da África. Teólogos e estudiosos ligados discutiam com maior freqüência no século XIX, a possibilidade de distinção entre assuntos da religião e do Estado, no entanto os valores religiosos continuavam a ser vistos como elementos importantes para a vida pública. Com o modernismo islâmico (datado do fim do século XIX e início do século XX) que visava responder às críticas externas relacionadas à influência da religião na vida cotidiana dos muçulmanos prevaleceu por algumas décadas uma tentativa de reavivamento do pensamento e prática islâmica, que consistia na crença de que o Islã poderia ser flexível para adaptar-se aos "tempos modernos". No entanto, no final do século XX surgiram movimentos que ficaram conhecidos sob a égide do islã político e visavam o fortalecimento do compromisso com o Islã. Neste contexto ocorreu um embate entre noções de secularismo e a religião islâmica em que de um lado existia a tentativa (de cunho secular) de definir o Islã como um elemento de crença pessoal; enquanto que do outro estava a perspectiva de reinserção da Sharia (lei islâmica que teria sido revelada no Alcorão e foi interpretada por juristas ao longo dos séculos VII e IX) e dos valores islâmicos nos Estados (John L. ESPOSITO, 2004).
}

Mandrágora, v.26, n. 1, 2020, p.49-81 
sendo que a diferença principal entre eles está na aplicação das mencionadas leis; fator este que está relacionado ao balanço entre a lei islâmica (a Shar'ia, tal qual interpretada por juristas das escolas de pensamento jurídico islâmico) e a lei secular (Abdullahi Ahmed AN-NA'IM, 2002).

Os direitos das mulheres foram inseridos na discussão das novas leis de família (ou código de status pessoal) em países como Egito, Turquia² e Irã (Abdullahi Ahmed AN-NA'IM, 2002). No Irã, por exemplo, reformas sociais e jurídicas conduzidas pelo Xá Mohammad Reza Pahlavi na década de 1960, sob a égide da Revolução Branca (1963), incluíram os âmbitos social, econômico e jurídico, visando demonstrar o tom secular do país persa que almejava tornar-se uma potência econômica na região do Golfo Pérsico. Entre as reformas sociais realizadas a mais intensa e internamente discutida, sobretudo junto aos líderes religiosos xiitas (Ulemás), foi acerca dos direitos das mulheres, como direito ao voto e a retirada da obrigatoriedade do uso do véu em locais públicos; envolvendo desta forma, grupos de pressão como a Organização das Mulheres do Irã (OMI), uma organização oficial ligada ao governo iraniano³.

Em 1967 foi aprovada a Lei de Proteção à Família que transformou de forma substancial aspectos da interpretação da Shar'ia e a aplicação deste entendimento humano (juristas e estudiosos) que promoviam desigualdades entre homens e mulheres. Um exemplo é o direito de iniciar um pedido de divórcio. Do ponto de vista teórico homens e muIheres possuem o direito de iniciar o divórcio, no entanto um pedido iniciado por uma mulher tinha que percorrer um caminho judicial, no âmbito das cortes de família, enquanto o homem pode utilizar-se da prerrogativa do divórcio unilateral, por repúdio, conhecido como talaq (Ziba MIR-HOSSEINI, 2003, p. 1-38).

\footnotetext{
No caso da Turquia, por exemplo, foi elaborado e a passou a vigorar em 1926 um código civil baseado no modelo do código civil suíço (Abdullahi Ahmed AN-NA'IM, 2002, p. 27-28).

3 De acordo com a pesquisadora iraniano-francesa Azadeh Kian-Thiébaut (2008) a princesa Ashraf Pahlavi, irmã do Xá Mohammad Reza Pahlavi, foi figura importante na discussão e defesa dos direitos das mulheres por ter criado a Organização das Mulheres do Irã (OMI), organização esta que, paradoxalmente, era ligada ao governo iraniano e buscava alterações nos direitos das mulheres iranianas, porém, sem questionar o que Azedah Kian-Thiébaut (2008) denomina de "natureza patriarcal e sexuada do Estado" (Azadeh KIAN-THIÉBAUT apud Carmem RIAL, 2008, p. 148-149; 154).
} 
Para discutir e compreender as interações entre gênero, sexualidade, Islã e sua aplicação nas leis de família muçulmanas é de extrema relevância descrever os elementos advindos da tradição religiosa (Shar'ia, jurisprudência islâmica clássica (Fiqh) e ahadith) e dos valores advindos dos costumes locais/nacionais. Os elementos da tradição religiosa que foram interpretados por juristas e estudiosos religiosos, principalmente no período formativo do Islã (séculos VII e IX), trouxeram concepções específicas e constitutivas dos papeis de gênero na sociedade, normatizando os corpos e a sexualidade de homens e mulheres (Kecia ALI, 2003; Leila AHMED, 1992).

As Leis de Família Muçulmanas - entendidas para os propósitos deste artigo como o conjunto de leis que orientam aspectos como a celebração de contratos de casamento, o direito ao pedido de divórcio, a custódia dos filhos gerados no casamento - refletem os diferentes níveis de complexidade da jurisprudência islâmica, como argumenta assertivamente Azizah Al-Hibri (1997), em artigo acerca das leis muçulmanas e as tentativas de redefinir os direitos das mulheres. Tendo em vista tal complexidade e a necessidade de entendê-la em pleno século XXI, objetiva-se, por meio deste artigo, apresentar e discutir os principais aspectos da intersecção entre gênero, sexualidade e Islã refletidos nas leis de família muçulmanas e, sobretudo trazer a crítica feminista islâmica (desenvolvida no Oriente Médio e Norte da África a partir de 1990) aos discursos que legitimam práticas normativas para a expressão de sua sexualidade de mulheres e homens e compõem as leis de família.

Para tanto, o artigo se divide em duas seções e possui, como base, a discussão e reflexão acerca do material bibliográfico elaborado acerca da interação entre gênero, sexualidade e direitos das mulheres em uma perspectiva da crítica feminista islâmica. A primeira seção Interpretação da Jurisprudência Islâmica clássica (fiqh): teoria e prática acerca da das Leis de Família Muçulmanas, discute como foi forjada ao longo dos séculos a jurisprudência (fiqh) que ainda no século XXI é determinante para o desenvolvimento das Leis de Família em diversos países do Oriente Médio e Norte da África. Como a análise das especificidades dos países da região mencionada esta além do escopo deste artigo, optou-se em apresentar as características comuns que compõem as Leis 
de Família muçulmanas de modo mais sintético, ou seja, um denominador comum entre os países que aderem à Shar'ia, representado pelos entendimentos acerca do casamento, divórcio e suas implicações para os direitos das mulheres com destaque para algumas diferenças entre as escolas de pensamento jurídico. Desta forma, em alguns momentos são apresentados exemplos de países (Marrocos, Turquia, Irã) e escolas de pensamento (Maliki, Hanafi - de corrente sunita - e a Jafari, da corrente xiita) como um recurso para a observação e compreensão de características apresentadas.

A segunda seção, As Leis de Família Muçulmanas: elementos e crítica feminista islâmica, apresenta questões centrais para a análise da intersecção entre gênero, sexualidade e Islã, bem como a crítica feminista islâmica feita às leis de família. Assim, são destacadas as seguintes questões: a) os costumes e normas sociais acerca da expressão da sexualidade fora de um casamento; b) os direitos e deveres conjugais diferenciados entre homens e mulheres e seu caráter interdependente, como por exemplo, a obrigação da mulher de obedecer ao seu marido (inclusive estar disponível para relações sexuais) e o dever do homem de garantir a manutenção de sua esposa (principalmente financeira); e c) o direito da mulher de iniciar um pedido de divórcio e estabelecer o próprio contrato de casamento, eliminando assim a necessidade de tutela/guarda exercida por seu pai ou por outra figura masculina da família.

\section{DESENVOLVIMENTO E INTERPRETAÇÃO DA JURISPRUDÊNCIA ISLÂMICA CLÁSSICA (FIQH): TEORIA E PRÁTICA ACERCA DAS LEIS DE FAMÍLIA MUÇULMANAS}

A jurisprudência islâmica clássica (fiqh) foi desenvolvida substancialmente entre os séculos VII e IX e o status da mulher nas sociedades de população muçulmana, bem como as Leis de Família derivam da estrutura social e religiosa que assume uma organização patriarcal do Estado. No entanto, cabe mencionar que a ascensão do patriarcado não era uma característica isolada dos países do mundo muçulmano, visto que tal modelo era observado também no Império Bizantino e no Império Persa 4 .

Azizah AL-HIBRI (1997); Leila AHMED (1992). 
Com o desenvolvimento do patriarcado e a coexistência e a posterior cooptação pela via do costume de práticas pré-islâmicas um fato paradoxal, no que diz respeito à atuação das mulheres na sociedade, pode ser descrito. A atuação feminina nos anos iniciais do Islã (ainda na segunda metade do século VII) era mais evidente, como é observado pela influência da primeira mulher do Profeta Maomé - Khadija - e foi gradualmente alterada já que com a introdução do Islã a mulher passou a ser vista como alguém que tinha que ser tutelada por figuras masculinas próximas, tais como o pai, um irmão ou um tio (Leila AHMED, 1992, p. 41-63; John L. ESPOSITO e Natana J. DELONG-BAS, 2001).

Leila Ahmed (1992) aponta que embora as práticas matrimoniais do período pré-islâmico na península arábica fossem distintas, relacionadas a costumes, não indicassem necessariamente a desigualdades entre homens e mulheres seria possível argumentar que as mulheres possuíam certa autonomia sexual que foi alterada sob a influência do Islã. Era neste contexto em que viveu a Khadija, primeira mulher de Maomé. Viúva e economicamente independente ela participava da vida pública, do comércio, casou-se com um homem mais jovem e permaneceu em um casamento monogâmico, um dos arranjos de casamento já presente no período pré-islâmico. Já Aisha representa a mudança observada na transição da Arábia pré-islâmica para a consolidação do Islã, principalmente se tratando da formação clássica da lei de família muçulmana, sobretudo as alterações e acomodações de costumes pré-existentes (como o casamento de meninas mais novas) e valores islâmicos relacionadas aos arranjos de casamento.

As principais fontes que compõem a jurisprudência islâmica clássica (fiqh) são o Alcorão e as ahadith (tradições e ditos do Profeta Maomé) que foram interpretadas por juristas e estudiosos e posteriormente aplicadas nas diferentes sociedades de população muçulmana no Oriente Médio e Norte da África. Quando essas fontes não eram suficientes para resolver questões da vida prática dos crentes os estudiosos da religião (da Ciência Corânica), recorriam a um movimento de reflexão e interpretação crítica (ijtihad); além do movimento de exegese (tafsir) que visava expressar uma melhor compreensão da mensagem contida nas fontes religiosas. Tal expressão ocorria por meio de uma linguagem comum 
para alcançar o sentido principal dos textos (cujo foco permanecia na tradição datada do início do Islã, sem acrescentar visões pessoais acerca do tema) ou pela busca de uma reflexão crítica acerca de um possível significado oculto nos textos e que deveria ser compreendido5.

Os juristas e estudiosos da religião elaboraram nos primeiros séculos do Islã (VII e IX) diferentes escolas de pensamento, aspecto intrinsecamente ligado às comunidades e à cultura em que estavam inseridos (Azizah AL-HIBRI, 1997). Assim sendo os diferentes países da região do Oriente Médio e Norte da África escolheram uma escola de pensamento para seguir (entre as escolas Hanafi, Maliki, Sharif e Hanbali, na corrente sunita e Jafari, na corrente xiita, por exemplo) e aplicar a lei islâmica. No entanto, cabe ressaltar que no século XIV os juristas muçulmanos da corrente sunita passaram a declarar que "as portas da ijtihad deveriam ser fechadas" e que a partir de então os juristas deveriam basear suas decisões nas fontes religiosas e na jurisprudência já estabelecida ao invés de buscarem suas opiniões próprias para cada matéria em que fossem requisitados.

Desenvolveu-se neste contexto dos primeiros séculos do Islã uma narrativa fundamental para aquela que seria estabelecida como uma "argumentação positiva" quanto ao status das mulheres com relação aos seus direitos no período de transição e consolidação do Islã. O elemento central desta argumentação é o de que a introdução da nova religião permitiu uma mudança na base social que moveu os indivíduos de uma sociedade pautada pelo prevalecimento do parentesco de sangue e costumes tribais para uma comunidade em que a família suplanta a noção de lealdade tribal como base da organização da sociedade (John L. ESPOSITO e Natana J. DELONG-BAS, 2001, p. 12-20).

Entre estudiosos e clérigos islâmicos, se consolidou o entendimento de que a adesão das comunidades à nova religião permitiu o reconhecimento da condição humana das mulheres, ou seja, em comparação às formas de sociabilidade pré-existentes, as mulheres tiveram diversos aspectos de sua existência reconhecidos, como a sexualidade - mas também surge uma premissa de controle da mulher, enquanto são

Jamil ISKANDAR (2007, p. 111-121) desenvolve uma extensa análise sobre a teologia e filosofia implicadas na compreensão do Alcorão. 
condenadas práticas como o infanticídio (geralmente de meninas), o abandono de viúvas ou seu casamento com o homem mais próximo do marido falecido (Leila AHMED, 1992; Fatima MERNISSI, 1987, p. 17-24).

A construção de gênero presente na jurisprudência clássica (fiqh), ou seja, o entendimento humano de juristas e estudiosos acerca da Shar'ia (valores que representam o ideal da lei islâmica e foram revelados no Alcorão), detinha como característica central a desigualdade de gênero, principalmente no que diz respeito à compreensão dos direitos e deveres de homens e mulheres no casamento - desde a celebração do contrato de casamento, passando pela possibilidade de iniciar um divórcio, determinar a "natureza do casamento" como poligâmico ou não, além de questões como os direitos à herança e a determinação da custódia dos filhos gerados no casamento.

O casamento, definido de maneira unânime pelos membros das diferentes escolas de pensamento jurídico como um contrato, não estabelecia obrigações recíprocas aos cônjuges. O homem era visto como o provedor e guardião da mulher e a hierarquização de gênero era sustentada pelas interpretações feitas por juristas das fontes religiosas, tais como passagens do Alcorão e as tradições (ahadith), e posteriormente por meio da aplicação dos entendimentos alcançados pelos juristas na prática social. Leila Ahmed (1992, p.43-45) ressalta que o formato de casamento legitimado pelo Islã alterou o que a pesquisadora descreve como o "nexo da sexualidade e do poder entre homens e mulheres" e investiu aos pais (e posteriormente ao marido) a "propriedade" dos direitos da sexualidade do corpo feminino, sob argumentos de proteção e garantia da honra familiar.

Abdullahi Ahmed An-Na'im (2002, p. 1-22) argumenta que, apesar da suposta hegemonia intelectual e ideológica que a Shar'ia detinha junto aos países de população muçulmana, a lei secular, entendida como aquela não derivada das fontes religiosas e cuja legitimidade estava relacionada à vontade política de figuras de autoridade regionais, tornou-se um elemento central da dinâmica de transição legal/jurídica que ocorreu nos países de população muçulmana ao longo dos séculos XIX e XX, principalmente com a influência do poder imperial europeu na região desde o século XVI. 
Ao longo dos séculos XIX e XX, é possível observar uma tendência de grupos reformistas/progressistas no interior do Islã que visava responder às críticas externas ao status da mulher nas sociedades muçulmanas. O modernismo islâmico clamava pela reforma da tradição islâmica para atender às necessidades das sociedades modernas, o que incluía, por exemplo, a flexibilização das instituições políticas (John L. ESPOSITO, 2004). Esta tendência reformista moderna no interior do Islã argumentava que era possível aos muçulmanos serem modernos sem perder a fé, ou seja, as duas características não seriam necessariamente excludentes, como às vezes o olhar de fora (ocidental) ou o olhar interno (estritamente religioso) acreditava ou argumentava ser. Para tanto, era necessária uma abordagem seletiva do conhecimento que tinha sido revelado (como a Shar'ia, por exemplo) e da razão, que era fruto do entendimento humano e foi, posteriormente, codificada nas Leis de Família.

Os movimentos reformistas de maior relevância, principalmente no século XIX, emergiram no Egito, Indonésia e Índia e tinham como frentes de atuação reformas educacionais (ampliação do ensino e inclusão de temas como ciência e tecnologia) e reforma no sistema legal dos países, principalmente nos âmbitos civil/familiar, criminal e penal (John L. ESPOSITO, 2004). No Egito, por exemplo, o jurista islâmico egípcio Muhammad Abduh retomou no século XIX o princípio da ijtihad, questionando o que ele denominou de tradicionais interpretações religiosas por considerá-las violadoras de princípios do Islã, sobretudo pelo entendimento de Abduh de que abusos relacionados aos aspectos que regiam o âmbito familiar, tais como o divórcio e poligamia, eram cometidos por meio da aplicação de interpretações equivocadas ou pouco flexíveis dos valores do Islá.

O processo de codificação das Leis de Família Muçulmanas ou códigos de status pessoal ${ }^{6}$, ocorrido na primeira metade do século XX,

6 Ressalto que as Leis de Família possuem alterações relacionadas às identidades nacionais, culturais e costumes (e de acordo com a escola de pensamento jurídico adotada) dos países do Oriente Médio e Norte da África. Além disso, como explica Lynn Welchman (2007, p. 11-18) existe uma diferença com relação a forma com que tais leis são aplicadas: no Líbano e Jordânia estas são aplicadas por meio das Cortes de Shar'ia, separadas da Corte Civil, enquanto no Egito as Cortes de Shar'ia foram abolidas e as leis de família passaram a ser aplicadas. 
manteve a desigualdade de direitos e deveres entre homens e mulheres já presentes na jurisprudência islâmica clássica (fiqh) como foi anteriormente descrito, porém com poucas exceções. Uma delas é o caso da Tunísia, que assim que alcançou sua independência e elaborou seu código de status pessoal em 1956 proibiu a poligamia, direito reservado aos homens e que permaneceu uma questão delicada para outros países que compõem juntamente com a Tunísia a região do Magreb (Tunísia, Argélia, Marrocos) e levaram algumas décadas para restringir, mesmo que parcialmente, o direito à poligamia.

A manutenção da desigualdade entre homens e mulheres suscitou questionamentos por parte de parcela das mulheres muçulmanas, fato este que deu origem a uma plataforma para a atuação de movimentos sociais que visam a alterações no seu status nas diversas sociedades de população muçulmana.

Apesar da aparente controvérsia entre os direitos das mulheres e a sua religião, até a primeira metade do século XX um movimento ativista pelos direitos das mulheres tomou forma em um momento singular em que as sociedades muçulmanas passavam por transformações internas por conta do impacto do colonialismo europeu, do embate entre a tradição e a modernidade, do discurso reformista e do nacionalismo, sobretudo sob a égide de movimentos de independência e a chamada para a formação de Estados independentes (Ziba MIR-HOSSEINI, 2009; Margot BADRAN, 2009).

Em resposta às demandas de movimentos de mulheres acerca da necessidade de refletir acerca das leis e códigos de status pessoal desenvolvidos anteriormente, com o intuito de propor alterações ao texto e em sua aplicação junto às cortes especais, surgiu um discurso (em sua maior parte conduzido por homens) que apresentava argumentações para tentar acomodar as aspirações femininas ligadas à igualdade de direitos com base no retorno às fontes religiosas, como o Alcorão, ao trazer à luz a questão dos direitos das mulheres no Islã.

$O$ referido discurso apontava para os entendimentos de juristas e estudiosos, desenvolvidos nos primeiros séculos do Islã (VII ao IX), de que em comparação ao período anterior ao surgimento do Islã (no século VII, na Península Arábica) as sociedades viviam o que se conven- 
cionou chamar de período pré-islâmico em que as pessoas adoravam diversos deuses, acreditavam em mitos e espíritos e, principalmente prevalecia o princípio da sobrevivência. Tal princípio naturalizava práticas com relação às mulheres, tais como o abandono de viúvas e a morte de meninas, que foram substituídas por um conjunto crenças, aspectos morais, direitos e obrigações da nova comunidade. Seguindo esta linha de raciocínio argumentava-se que a partir da adesão das comunidades ao Islã as mulheres passaram a ter sua condição humana reconhecida, embora a religião considere que não existam direitos, deveres ou até mesmo punições iguais para homens e mulheres (Leila AHMED, 1992, p. 25-38; 41-45).

Um exemplo historicamente mais recente e marcante do discurso que aponta, na história do Islã, vestígios de uma melhoria no status da mulher na sociedade é o do teólogo iraniano Ayatollah Mortedha Motahari (falecido em 1979). Partindo das críticas acerca da relação entre o Islã e os direitos das mulheres, o clérigo passou a fazer discursos em que se posicionou sobre o tema, argumentando que, embora o Islã não tenha garantido os mesmos direitos aos homens e às mulheres, a totalidade dos direitos a elas definidos não é menos importante se observar o período pré-islâmico. Enfatiza, nesta linha de raciocínio, a atuação de mulheres que atingiram alta posição junto à comunidade islâmica, como Khadija (primeira esposa do Profeta) e Fátima Zahra (filha do Profeta, mãe de dois Imames e considerada pelos xiitas do duodécimo como uma interventora dos crentes junto a Deus por fazer parte do grupo dos quatorze puros) ${ }^{7}$.

Além disso, Ayatollah Mortedha Motahari (2008) argumenta que a crítica acerca da não observância dos direitos da mulher advém da não compreensão externa de que, para o Islã, em contraponto com o raciocínio que orienta os sistemas jurídicos de países ocidentais, as diferenças entre homens e mulheres são tidas como inatas e naturais, e que a discussão seria, portanto, sobre observância da justiça e os direitos naturais que conduziriam ao desenvolvimento da família e sociedade.

No contexto internacional, por exemplo, cabe comentar o desenvolvimento de um posicionamento conjunto dos países da Organização

Ayatollah Mortedha Motahari (2008, p. 113-125). 
de Cooperação Islâmica ${ }^{8}$ (OIC, sigla em inglês) feito em 1990 por meio da elaboração da Declaração do Cairo sobre Direitos Humanos no Islã que apresentou uma visão islâmica sobre os direitos humanos universais, tal qual observado na Declaração Universal dos Direitos Humanos (em documento adotado na Assembleia Geral das Nações Unidas em 1948), e firmou posicionamento em relação à Convenção sobre a Eliminação de Todas as formas de Discriminação contra a Mulher (CEDAW, de 1979), que havia sido ratificada com restrições em alguns países de população muçulmana. A Declaração do Cairo sobre Direitos Humanos no Islã argumentou que para os países membros a Shar'ia (é importante que neste caso leia-se figh, ou seja, a jurisprudência advinda do entendimento humano acerca da revelação da lei contida no Alcorão) era uma espécie de limite para a concretização de alguns artigos presentes na Declaração Universal dos Direitos Humanos. A crítica apresentada à Declaração do Cairo sobre Direitos Humanos no Islã foi a de que ela serviria como uma base argumentativa para que os países membros da OIC prolongassem suas ressalvas com relação a artigos da Cedaw que de alguma forma iam de encontro às disposições das leis de família nacionais (Muhammad Khalid MASUD, 2012, p. 113-115; Declaração do Cairo sobre os Direitos Humanos no Islã, 1990).

Em paralelo ao supramencionado discurso de equidade e complementaridade de direitos e deveres entre homens e mulheres no Islã e além das relações estabelecidas no âmbito nacional entre o denominado feminismo secular ${ }^{9}$ e o discurso com bases religiosas que clamava pelos direitos das mulheres e pela igualdade através de argumentos advindos de interpretações reformistas de textos sagrados se organizaram

8 Denominada inicialmente Organização da Conferência Islâmica e formada em 1969 como uma conferência entre países de população muçulmana que visava salvaguardar os valores e interesses muçulmanos no cenário político internacional, a organização possui uma representação permanente na Organização das Nações Unidas (ONU) e ao longo das últimas décadas seu escopo de atuação internacional e influência político-social esteve relacionado à apresentação de valores derivados da jurisprudência e fontes islâmicas para tratar de formas de proteção dos direitos humanos (Víctor Luis Gutiérrez CASTILLO, 2014, p. 14-21).

9 Para o propósito do presente artigo o feminismo secular é entendido como um movimento desenvolvido entre o final do século XIX e meados do século XX e ligado, inicialmente, aos movimentos de liberação nacional frente ao colonialismo europeu (principalmente francês e britânico) no Oriente Médio e Norte da África que Ihe conferia ao mesmo tempo um caráter nacionalista. 
e inseriram as diferentes demandas das mulheres e suas experiências na sociedade.

Neste contexto já existia a busca ir além da noção de equidade/ complementaridade anteriormente desenvolvida. Ao longo da década de 1990 se ampliou na cena social e política do Oriente Médio e Norte da África o denominado feminismo islâmico ${ }^{10}$, uma construção discursiva que através de uma interpretação independente (ijtihad) da doutrina islâmica (Alcorão, Shari'a e fiqh) questionava o modelo patriarcal de família observado nos diferentes países sob a forma das leis de família (ou dos códigos de status pessoal), argumentando que o mesmo não era condizente com o princípio da igualdade humana e justiça de gênero presentes no Alcorão, ou seja, o conflito estava relacionado à interpretação conferida aos textos religiosos e posteriormente às práticas sociais que são sustentadas por aqueles e vice-versa (Asma BARLAS, 2001; Margot BADRAN, 2009; Ziba MIR-HOSSEINI, 2011).

Embora apresentem projetos com base em elementos analíticos diferenciados, de um lado com base na leitura e reinterpretação do Alcorão e de outro o desenvolvimento de uma análise critica acerca da jurisprudência islâmica, as expoentes do feminismo islâmico argumentavam que um importante obstáculo para a igualdade de gênero estaria na forma com que juristas entendiam e legislavam acerca da relação entre a noção da autoridade masculina - expressa em conceitos como de obediência por parte da mulher no âmbito familiar em contrapartida da proteção e amparo financeiro do marido -, elemento este que teria sua concepção originária quando da revelação do Alcorão (seria a Shar'ia), porém foi objeto de interpretação humana (principalmente entre os séculos VII e IX) e assim internalizado nas leis de família como uma espécie de produto do contexto histórico e social.

A preocupação com relação à compreensão e posterior crítica aos elementos éticos, históricos, sociais e legais que conduziram à construção jurídica da noção da autoridade masculina que ainda é inspiração para as leis de família em contexto muçulmano é observada, por

10 Amina Wadud (1999), Ziba Mir-Hosseini (1999; 2003; 2009; 2011), Asma Barlas (2001; 2002), Fatima Mernissi (1987; 1992), Kecia Ali (2003; 2013) figuram entre as principais expoentes do movimento. 
exemplo, nos trabalhos desenvolvidos por Ziba Mir-Hosseini. A referida antropóloga muçulmana aponta que o conceito qiwama ${ }^{11}$ - que deriva do entendimento jurídico clássico da referência de "protetor/provedor" (qawaamun) na surata n.4 (An Nissá - as mulheres), versículo 34 do Alcorão - continuou a ser utilizado como uma espécie de elemento racional para justificar a desigualdade no âmbito familiar, visto que o homem em seu papel de "protetor/provedor" da mulher possui direitos diferenciados, como à poligamia, ao pedido de divórcio unilateral por repúdio à mulher, a possibilidade de punir fisicamente a esposa "desleal ou rebelde" (nushuz). Neste entendimento da jurisprudência clássica a mulher "correta" deve ser obediente (qanita) ao marido, tem sua sexualidade e a liberdade de movimento controlados.

\section{AS LEIS DE FAMÍLIA MUÇULMANAS: ELEMENTOS CONSTITUINTES E A CRÍTICA FEMINISTA ISLÂMICA}

As Leis de Família Muçulmanas regem, conforme mencionado inicialmente, aspectos da vida cotidiana e privada dos crentes muçulmanos, tais como a contração do casamento, o direito ao pedido de divórcio, a custódia dos filhos gerados no casamento e principalmente no que diz respeito aos direitos das mulheres traz uma noção de controle de sua sexualidade antes e após o casamento, visto que as práticas sexuais são criminalizadas se ocorrerem fora do casamento e após este as mulheres têm sua sexualidade "transferida e controlada" sob a proteção do marido.

Analisar as posições adotadas pelas principais escolas de pensamento, como a Hanafi, Malaki (de corrente sunita) e a escola xiita (Jafari) é relevante para retomar as três questões centrais para a análise da intersecção entre gênero, sexualidade e Islã, bem como seus reflexos nas Leis de Família Muçulmanas e a crítica feminista islâmica; a saber: a) os costumes e normas sociais acerca da expressão da sexualidade fora de um casamento (sobretudo a noção de preservar a pureza da mulher, ou seja, sua virgindade que era relacionada a honra da mesma e de sua

\footnotetext{
Ayesha Chaudhary (2008) e Sa'diyya Shaikh (1997) também fornecem uma análise histórica da compreensão do conceito de qiwama, que tradicionalmente foi visto por seus críticos como uma construção patriarcal que legitimou a hierarquia de gênero no âmbito familiar, e discutem a interpretações reformistas do referido conceito.
} 
família); b) os direitos e deveres conjugais diferenciados entre homens e mulheres e seu caráter interdependente, como por exemplo a obrigação da mulher de obedecer ao seu marido (inclusive estar disponível para relações sexuais) e o dever do homem de garantir a manutenção (principalmente financeira); e c) o direito da mulher de iniciar um pedido de divórcio e estabelecer o próprio contrato de casamento, eliminando assim a necessidade de tutela/guarda exercida por seu pai ou por outra figura masculina da família.

Após tal levantamento e discussões serão apresentados e discutidos os principais aspectos da crítica feminista islâmica (desenvolvida no Oriente Médio e Norte da África a partir de 1990) aos discursos que legitimam práticas normativas para a expressão de sua sexualidade de mulheres e homens e compõem as leis de família.

Quanto à primeira questão, os costumes e normas sociais acerca da expressão da sexualidade fora de um casamento, dois aspectos são extensamente discutidos: a noção de preservar a pureza da mulher, ou seja, sua virgindade que era relacionada à honra da mesma e de sua família; e a criminalização da sexualidade por meio das restrições de Zina (que advém de uma tradição islâmica clássica e foram retomadas nas últimas décadas do século XX, com o advento do Islã nos âmbitos político e social).

O Islã desenvolveu costumes e normas para lidar com o instinto sexual, regulamentando-o de forma a permitir a sua satisfação e ao mesmo tempo manter a sociedade longe de praticas que prejudiquem a sociedade, sendo que de acordo com Fathi Yaken (1992) o casamento foi compreendido como o único caminho moral e legal para atender ambas as demandas.

A ativista pelos direitos das mulheres e pesquisadora egípcia $\mathrm{Na}$ wal El Saadawi (1931), cujo trabalho acadêmico e ativista influenciou as feministas islâmicas da década de 1990, desenvolveu uma extensa obra reflexiva e crítica acerca da mulher no Islã, sobretudo ao problematizar a manutenção de práticas culturais como a circuncisão feminina na sociedade egípcia, e no livro A face oculta de Eva: as mulheres do mundo Árabe (2002), se dedicou também ao debate da questão da virgindade imposta com especial ênfase às mulheres, descrevendo práticas observadas em seu país na condição de médica psiquiatra. 
Antes de apresentar as discussões em torno de questão como a circuncisão feminina e a preservação da virgindade da mulher até o casamento Nawal El Saadawi (2002) argumenta inicialmente que "a trilogia composta pela política, religião e sexo é amais sensível de todas as áreas de qualquer sociedade" (2002, p. 19) e reforça que tal sensibilidade pode ser mais latente em países de origem rural, em que segundo a autora as formas de relacionamento características do período de formação do Islã ainda possuem influência e que somado a este aspecto verificava-se nas ultimas décadas do século XX uma campanha que utilizava a religião e seus preceitos para fins outros (econômicos ou políticos) que confinaram suas nações à retomada de aspectos religiosos disciplinares e morais aos seus crentes. Nawal El Saadawi (2002, p. 2122) também descreve que a condição da mulher no Islã neste contexto é uma espécie de produto do embate e enlace entre a força religiosa, os costumes/ normas culturais, e a manutenção do patriarcado.

Com base no contexto social da sociedade egípcia em que se insere, Nawal El Saadawi (2002, p. 25-31) explana que na década de 1930 era comum que as meninas, ainda muito jovens e independentemente de sua classe social, fossem submetidas a um costume que tinha como um dos objetivos controlar a manifestação da sexualidade das mesmas na adolescência e fase adulta - a circuncisão (a remoção do clitóris). Além da experiência acima citada, ao passo em que crescem, as meninas são confrontadas com a questão da virgindade, visto que aprendem que devem tomar cuidados especiais com seus órgãos genitais, vivenciando um receio com relação a proteção da área que incluía a repressão de suas vontades ou desejos naturais e cuidados com movimentos que realizavam, processo este que a referida autora assim descreve:

A educação de uma garotinha na sociedade árabe constitui-se de uma espécie de recomendações sobre os assuntos considerados prejudiciais, proibidos, vergonhosos ou pecaminosos pela religião. A criança, portanto, é trinada para reprimir suas vontades próprias, esvaziando-se de quaisquer ânsias ou desejos autênticos e espontâneos ligados a seu próprio ser, e devem preencher esse vazio com os desejos dos outros. A sua educação trasnforma-se num lento processo de auto-anulação, na supressão gradativa de suas vontades e personalidade, deixando 
intacta apenas a aparência externa, o corpo, um monte de músculos, ossos e sangue sem vida, movimentando-se como uma boneca a de que se dá corda. Uma garota, tendo perdido sua personalidade, sua capacidade de pensar livremente e de usufruir de suas vontades próprias, fará tudo aquilo que alguém Ihe mandar, tornando-se um fantoche em suas mãos, à mercê de suas decisões (Nawal EL-SAADAWI, 2002, p. 33-34).

Embora El-Saadawi (2002) compreenda que os homens de várias idades também eram alcançados pela prática disciplinadora que impõe uma moral religiosa que impede o ato sexual fora de um contrato legal de casamento, a autora argumenta que, nestas sociedades em que, além disso, também ocorre a segregação dos sexos, a menina/ mulher é ainda mais atingida pois pode se tornar objeto de desejo de seus familiares do sexo masculino mais próximos (como irmãos, tios, primos) ou pessoas do seu entorno familiar e, desta forma, uma vítima em potencial de uma violação sexual que lhe custaria a honra (pessoal e da família). Ao homem, no entanto, apesar de infringir costumes e tradições religiosas não passa pelo mesmo processo de perda da honra que a mulher e, em alguns casos, pode apenas ter que casar-se com a mesma para legalizar a situação e resgatar a honra familiar.

Já a criminalização da sexualidade por meio das restrições de Zina (restrições estas que advém de uma tradição islâmica clássica e foram retomadas nas últimas décadas do século XX, com o advento do Islã nos âmbitos político e social) é um dos temas discutidos pela feminista islâmica e iraniana Ziba Mir-Hosseini (2011) em um extenso artigo, denominado Criminalising Sexuality: Zina Laws as violence against women in muslim contexts. Antes de seguir com a argumentação crítica de Ziba Mir-Hosseini (2011), retomo de forma breve aspectos da concepção islâmica clássica acerca da zina enquanto uma ofensa aos princípios do Islã, conforme apresentado inclusive no Alcorão.

Na concepção islâmica clássica, como descreve Fatima Mernissi (1987, p. 58-61), a palavra zina surgiu nos primeiros anos da formação do Islã (século VII) e era utilizada para designar uma relação sexual considerada ilícita, ou seja, uma relação entre duas pessoas que não possuem um vínculo matrimonial entre si. A transgressão representada pela zina, reali- 
zada por pessoas solteiras ou casadas, deveria ser punida, principalmente quando um dos envolvidos fosse casado, figurando assim um adultério.

No Alcorão uma série de versículos da surata ${ }^{\circ} 24$, intitulada $A n$ Nur (A Luz), traz as descrições das possíveis punições para as pessoas que cometem a zina, que variam desde açoites aos envolvidos, como, por exemplo, a aplicação de cem açoites para ambos os transgressores (dependendo das condições civis deles, ou seja, seu estado civil, já que uma punição maior é reservada aos casados que cometem o adultério poderia ser ampliada), até a exclusão social tendo em vista a natureza desrespeitosa do ato ${ }^{12}$. A punição no caso da zina entendida como adultério (Alcorão, 24:2) é tida, conforme argumenta Ziba Mir-Hosseini (2011) como uma das poucas recomendações neutra de gênero ao descrever uma punição igual para homem e mulher, ou seja, a hierarquia de gênero é relativizada neste contexto de punição de uma transgressão considerada grave tendo em vista os valores do Islã.

Além das punições para os envolvidos na zina a surata $n^{\circ} 24$ ainda descreve as consequências para quem comete o crime de acusação falsa contra uma pessoa (alegando que ela cometeu tal transgressão), mas não capaz de conseguir comprovar com as quatro testemunhas necessárias (de acordo com a passagem 24:4 do Alcorão). Neste caso, àquele que difama "pessoas castas" deveria receber oitenta açoites e seus testemunhos futuros em qualquer situação não seriam aceitos.

Ziba Mir-Hosseini (2011) retoma a questão de que de acordo com a tradição islâmica clássica "[...] qualquer ato sexual fora de um casamento legal é um crime. A principal categoria deste tipo de crime é denominada zina, definida como qualquer forma de contato sexual ilícito entre homem e mulher (2011, p. 7, tradução livre)" "13, sendo que de acordo com a pesquisadora o registro deste tipo de punição foi raramente documentado na história islâmica e que com o processo de reforma dos sistemas legais (civil, criminal) de diversos Estados no início do século $\mathrm{XX}^{14}$ tal lei tornou-se obsoleta.

\footnotetext{
Alcorão (24:2-9).

13 [...] any sexual contact outside a legal marriage as a crime. The main category of such crimes is zina, defined as any act of illicit sexual intercourse between a man and a woman.

14 Embora pareça existir um consenso de que historicamente poucos registros da aplicação de punições relacionadas à zina alguns episódios ocorreram no final do século XX, como, por exemplo, no Afeganistão (John L. ESPOSITO, 2004).
} 
A principal crítica desenvolvida por Ziba Mir-Hosseini (2011) é a de que com o ressurgimento do Islã como força política e social no final do século XX o status das-restrições de zina foi alterado por meio de uma revisão dos entendimentos jurídicos acerca dos aspectos criminalizados (incluindo discussões acerca do sexo consensual em que ambas as pessoas envolvidas são solteiras, mas relativizando a questão dos abusos sexuais contra mulheres), bem como a codificação das restrições no sistema penal e sua posterior aplicação. A reedição das restrições de zina gerou precedentes para uma espécie de "violência autorizada" contra as mulheres, desenvolvida por elementos não-estatais ou comunidades, tendo em vista que dos casos mais recentes da aplicação de uma nova interpretação jurídica da zina as mulheres foram os principais alvos de punições mais severas, tais como prisão ou castigos físicos. Com o intuito de ampliar o debate iniciado por campanhas em países como a Nigéria, Paquistão e Irã acerca da descriminalização do sexo consensual Ziba Mir-Hosseini (2011) discute que as restrições de zina podem ser questionadas em seu interior, ou seja, pela critica feminista do Islã, e em conjunto com os princípios dos Direitos Humanos.

De acordo com Ziba Mir-Hosseini (2011, p. 16-19) embora as restrições e punições da zina tenham sido desenvolvidas na jurisprudência clássica com "o intuito de salvaguardar a ordem sexual, a honra pessoal"15 (Ziba MIR-HOSSEINI, 2011, p. 18, tradução livre) e concebidas como neutras do ponto de vista do gênero ao prescrever sanções iguais a homens e mulheres condenados por seus atos ilícitos, e ao mesmo tempo proteja a mulher de uma acusação falsa contra ela; as referidas restrições ao serem retomadas no fim do século XX já se apoiavam em outras construções jurídicas advindas da compreensão da relevância conferida ao casamento e o entendimento da necessidade da mulher cobrir seu rosto e corpo e agir de acordo com uma "conduta de modéstia" que, por sua vez, teve a construção discursiva de sua importância (principalmente o uso do véu islâmico, o hijab uma das possíveis apresentações da cobertura feminina) em um processo recente, no século $\mathrm{XIX}$ que marca o encontro de diferentes sociedades muçulmanas com as potenciais coloniais europeias, com ênfase França e Inglaterra.

$15[\ldots]$ sought to safeguard sexual order, personal honor. 
Da construção jurídica islâmica clássica acerca do casamento teria sido extraída a noção de que a sexualidade da mulher seria uma espécie de propriedade adquirida pelo marido mediante a celebração do contrato de casamento; aspecto que é reforçado pela ênfase na castidade e pureza sexual prescrita antes do casamento, durante o casamento (na relação exclusiva entre os cônjuges) e quando da dissolução do casamento, por divórcio. Além disso, o casamento era enfatizado pelas diferentes escolas jurídicas islâmicas clássicas como um elemento central para garantir a satisfação sexual, evitando a incidência de relações sexuais fora de um contrato válido, e garantir a ordem social representada pela família muçulmana.

Por outro lado, o entendimento jurídico da necessidade da mulher cobrir seu rosto e corpo advém da interpretação recente (final do século $X I X)$ da noção de que os corpos femininos deveriam observar o princípio da modéstia previsto na relação entre os sexos, principalmente nos espaços públicos e privados reservados de acordo com o sexo ao cobrirem certas partes do seu corpo. De acordo com Ziba Mir-Hosseini (2011) as diretrizes da jurisprudência islâmica clássica "acerca da modéstia" no comportamento eram direcionadas aos homens e as mulheres, sobretudo no que diz respeito às atitudes relacionadas à interação com o sexo oposto (conforme descrito no Alcorão, 24:30). No entanto, as orientações acerca da vestimenta atingiam mais as mulheres do que os homens, principalmente no que diz respeito à cobertura de mais partes do corpo, como, por exemplo, o colo e o rosto.

Quanto à segunda questão central, os direitos e deveres conjugais diferenciados entre homens e mulheres e seu caráter interdependente, a estudiosa da religião norte-americana Kecia Ali (2003) salienta a relação de interdependência entre o dever da mulher de obedecer ao seu marido (inclusive estar disponível para relações sexuais) - e portanto um direito do homem - e o dever do homem de garantir a manutenção (principalmente financeira) de sua esposa.

Kecia Ali (2003) explica que para os juristas e estudiosos das escolas de pensamento que compõem a jurisprudência islâmica clássica (fiqh) ainda no século IX "de maneira geral, juristas compartilhavam uma visão do casamento que o considerava uma espécie de transferência 
ao marido, em troca do pagamento do dote, um forma de propriedade (milk) sobre sua mulher, e mais especificamente de seu órgão sexual (farj, bud) (2003, p. 169)"'16, legitimando assim as relações sexuais entre o marido e a mulher, bem como o direito do marido de controlar a mobilidade de sua esposa. Além disso, Kecia Ali (2003) destaca que o contexto inicial da jurisprudência islâmica clássica também sugere a existência de um entendimento de que o dever matrimonial mais importante da mulher era sua disponibilidade sexual, sendo tal dever inclusive separado daqueles relacionados ao serviço doméstico, por exemplo, e tinha como contrapartida essencial o direito ao sustento e proteção providos a ela pelo marido. Alguns juristas e estudiosos das escolas de pensamento jurídico sunita Maliki e Hanafi no século IX, como explana Ali (2003, p. 169-171), eram enfáticos ao argumentar que uma mulher casada não tinha as tarefas domésticas como obrigação segundo a qual era derivado seu sustento e proteção; mas sim a sua obediência e disponibilidade sexual.

Kecia Ali $(2003 ; 2013)$ aprofunda em suas analises uma preocupação com a relação estabelecida entre o sustento da mulher e seus deveres sexuais para com o marido e discute o predomínio dos direitos sexuais aos homens, tendo em vista a construção dos contratos de casamento, problematizando a questão de que ponto de vista legal/jurídico a mulher não tinha o mesmo direito ao sexo. Ou seja, paradoxalmente era possível ao homem divorciar-se de uma mulher por qualquer razão, sobretudo a desobediência aos seus deveres, enquanto a mulher tinha dificuldades para divorciar-se do marido mesmo quando ele não havia consumado o casamento (devendo a mulher, desta forma, aguardar uma decisão legal acerca de seu caso) ou quando o marido fazia um voto de abstinência sexual que fosse prejudicial para a esposa.

Cabe ressaltar e discutir que desta construção dos direitos interdependentes entre os cônjuges adquirem ao contraírem casamento existe também uma expressiva noção de obediência que possui um âmbito mais geral, ligado ao cumprimento das restrições e deveres impostos

${ }^{16}$ At its most basic, the jurists shared a view of marriage that considered it to transfer to the husband, in exchange for the payment of dower, a type ofowenship (milk) over his wife, and particularly over her sexual organ (farj, bud) (Kecia ALI, 2003, p. 169). 
pelo marido quando da celebração do casamento, e outro âmbito de caráter jurídico/legal, visto que a desobediência era passível de punições morais e a perda do direito da mulher ao sustento provido pelo marido.

A crítica feminista islâmica acerca desta questão da obediência que a mulher deveria apresentar ao seu marido, além do aspecto do controle da sexualidade feminina, baseia-se em uma busca pela interpretação livre (ijtihad) do Alcorão e demais fontes religiosas (ahadith e jurisprudência islâmica clássica - fiqh) para problematizar aspectos como a revisão dos direitos de mulheres e homens; a necessidade de observar a que o papel das representações contidas nas fontes sagradas em estruturar as práticas sociais e sexuais da sociedade e a manutenção de leituras/ interpretações masculinas das referidas fontes amplifica a importância de entender, segundo as palavras da pesquisadora e escritora paquistanesa Asma Barlas (2001, p. 117-121), quem interpreta o Alcorão e de que maneira para se pensar em formas de libertação da desigualdade que deriva de uma leitura particular (e patriarcal) do Alcorão e fontes religiosas.

Central na crítica de pesquisadoras e estudiosas como Sa'diyya Shaikh (1997) e Ziba Mir-Hosseini (2003) é a construção jurídica da noção da autoridade masculina, que mesmo sendo fruto do entendimento humano acerca da Shar'ia continuou como inspiração para as leis de família, principalmente no que diz respeito a interpretação da surata n.4 (An Nissá - as mulheres), versículo 34 do Alcorão, em que estaria expressa a interdependência entre a obrigação da mulher de obedecer ao seu esposo e o a obrigação dele de garantir a manutenção dela (o que inclui um abrigo, comida e vestuário necessários). A passagem acima mencionada aparece desta forma no Alcorão:

Os homens têm autoridade sobre as mulheres pelo que Deus os fez superiores a elas e por que gastam de suas posses para sustentá-las. As boas esposas são obedientes e guardam sua virtude na ausência de seu marido conforme Deus estabeleceu. Aquelas de quem temeis a rebelião, exortai-as, bani-as de vossa cama e batei nelas. Se vos obedecerem, não mais as molestais. Deus é elevado e grande (ALCORÃO, 4:34 apud Mansour CHALLITA (trad.), 2015, p. 83-84). 
Ziba Mir-Hosseini (2003,p. 3-13) expressa sua crítica ao que denomina visão tradicional da jurisprudência islâmica clássica ( $f i q h)$, segundo a qual o marido possui o papel de "protetor/provedor" de sua esposa e ela passa a ter direito à manutenção (nafaqa) após a consumação do casamento e pode perder o referido direito se apresentar um "estado de desobediência (nushuz)", ao argumentar que embora a palavra nushuz no sentido de desobediência do descumprimento dos deveres conjugais designasse uma atitude que teoricamente poderia ser tomada por ambos os cônjuges, geralmente é utilizada apenas na forma feminina para designar a atitude de rebelião da mulher e o fim de seus direitos matrimoniais.

Em sua exegese acerca do conceito de desobediência (nushuz) a pesquisadora Sa'diyya Shaikh (1997, p. 49-73) discute as implicações do entendimento da hierarquia de gênero que foi promovido pelos juristas das escolas de pensamento jurídico que compõem a jurisprudência islâmica clássica (fiqh) e questão da violência de gênero. O argumento central de sua exposição é o de que a passagem 4:34 do Alcorão (acima reproduzida) foi entendida tradicionalmente como elemento de tolerância com relação à violência contra as esposas, determinado um "castigo físico legítimo" para as mulheres que de alguma forma desobedecessem seus maridos. O problema deste entendimento clássico, ainda segundo Sa'Diuyya Shaikh (1997), é justamente o fato de este prover uma jurisprudência para violência doméstica múltipla, seja ela psicológica ou física (como a sexual), em casos em que a mulher é considerada "rebelde" por se recusar a ter relações sexuais com o marido ou quando está sob suspeita de infidelidade.

Já a terceira questão central para a discussão proposta para este artigo, a saber: o direito da mulher de iniciar um pedido de divórcio e estabelecer o próprio contrato de casamento, relaciona-se às duas primeiras questões centrais em certo grau. Conforme mencionado anteriormente, existia um consenso entre as escolas de pensamento jurídico de que o homem era a parte do casal que detinha certa facilidade para iniciar um divórcio de sua esposa por diversas questões, dentre elas a desobediência (configurada quando a mulher não cumpre seus deveres matrimoniais ou contraria as restrições que seu marido lhe impõe), enquanto a mulher tinha dificuldades para desempenhar tal ato, sendo 
necessária uma análise caso a caso, sendo que dependendo da escola de pensamento em que o país da esposa requerente era afiliado o resultado na maior parte dos casos de um processo na corte especial (de família) e uma decisão judicial.

As primeiras alterações nas leis de família quanto ao tema do divórcio ocorreram no início do século XX, com os editos desenvolvidos ainda no interior do Império Otomano. Em 1915 um primeiro edital imperial garantiu às mulheres o direito ao divórcio em casos específicos, como abandono por parte do marido. Já a Lei Otomana de Direito Familiar (1917) codificou tais alterações e ampliou as possibilidades da mulher pedir o divórcio, considerando situações como a impossibilidade do marido de manter economicamente a sua esposa, a comprovação de doença ou insanidade do marido, e o afastamento do marido de sua mulher por ação como abandono ou prisão (AN-NAIM, 2002, p. 26-27; John L. ESPOSITO e Natana J. DELONG-BAS, 2001, p. 50-51).

No Egito, por exemplo, onde a escola de pensamento Hanafi predomina nas Cortes da Shar'ia uma abordagem similar aquela presente da Lei Otomana de Direito Familiar (1917) foi promulgada durante a década de 1920 (com as leis n.25 de 1920 e de 1929). As referidas leis egípcias reconheciam algumas situações em que a mulher poderia iniciar um divórcio: o não cumprimento, por parte do marido, do dever de manter sua esposa; se o marido possui uma doença contagiosa; por maus tratos à mulher (John L. ESPOSITO e Natana J. DELONG-BAS, 2001, p. 51-54).

O direito da mulher de estabelecer o seu próprio contrato de casamento é um tópico complexo entre críticas feministas e juristas das escolas de pensamento. Discutirei esta ampla questão por meio da avaliação das seguintes questões: quais são os argumentos legais ou de costume que sustentam a existência legal da figura do wali (tutor/ guardião) na vida das mulheres? Qual seria a extensão do poder legal conferido a esta figura? Qual seria a alternativa reformista feminista capaz de permitir às mulheres a contração de seus próprios contratos de casamento sem comprometer sua identidade religiosa?

Um elemento discutido entre juristas e estudiosos das escolas de pensamento jurídico é o da centralidade da figura do wali (tutor/guardião) da mulher para a celebração do contrato de casamento e, além 
disso, qual deveria ser a extensão do poder jurídico/legal do wali com relação à filha. O wali é entendido pela jurisprudência clássica (fiqh) como uma figura jurídica específica exercida geralmente pelo pai (em casos em que ele não é presente a responsabilidade passa a ser do tio paterno) que possui a responsabilidade de cuidar de aspectos de interesse de mulheres menores de idade ou solteiras, tais como a contração de contrato de casamento e outros relacionados à propriedade/finanças.

A necessidade do wali foi entendida e construída no interior das escolas de pensamento jurídico como uma espécie de elemento positivo no sentido de proteger a mulher de suas ações emocionais ou de um casamento que não fosse adequado. De forma geral este argumento foi sustentado pela preocupação com a honra da mulher (e por extensão de sua família) expressa por uma visão patriarcal com relação à mulher e sua posição na família e sociedade ${ }^{17}$. No entanto, os critérios para determinar a extensão do poder legal do wali foram estabelecidos de forma diferente entre as escolas de pensamento jurídico, de acordo com o entendimento daquelas acerca da capacidade/maturidade do menor de idade que era tutelado pelo wali.

O entendimento da escola Hanafi é o de que o wali possui uma espécie de poder consultivo junto mulher legalmente maior de idade ${ }^{18}$ porque ela (assim como o homem) é livre neste contexto para contrair casamento em benefício próprio. Além disso, tal liberdade de ação deriva da noção de que como a mulher era considerada madura e capaz para administrar suas questões financeiras sem a interferência ou tutela de uma figura masculina também poderia usar esta prerrogativa para arranjar seu casamento sem a ação impositiva do wali (Azizah AL-HIBRI, 1997; John L. ESPOSITO e Natana J. DELONG-BAS, 2001, p. 14-17).

Já para a escola Maliki a extensão do poder de atuação do wali era maior, principalmente quando se tratava da escolha de um casamento

\footnotetext{
Azizah AL-HIBRI (1997); Mohammed FADEL (1998).

18 A maioridade de uma das partes que contraem o casamento (o homem ou a mulher) pode ser determinada pela idade da pessoa ou por um marco de sua vida, como a entrada na puberdade. Alguns códigos de família podem determinar de forma direta uma idade para a capacidade de contração de casamento, como, por exemplo, o Mudawana Marroquino de 2004, que estabeleceu em seu artigo $19^{\circ}$ que a idade mínima para casamento em 18 anos gregorianos para homens e mulheres (MUDAWANA, 2004).
} 
para uma mulher solteira (ainda que entendida como adulta devido à sua idade). Neste contexto um elemento presente na lógica de atuação dos juristas era o de que o consentimento de uma noiva bikr (casta e nunca casada) estava em um segundo plano de importância, sendo que cabia o pai da mulher em questão a possibilidade de declarar sua filha capaz (no sentido de emancipada) para que ela escolhesse o próprio marido e um casamento arranjado pelo wali só poderia ser evitado pela noiva se fosse possível comprovar que o futuro marido possuía algum tipo de doença grave.

Azizah Al-Hibri (1997) e Kecia Ali (2003), ambas vinculadas a movimentos intelectuais de crítica acerca do status da mulher nas sociedades muçulmanas, buscaram discutir uma alternativa reformista feminista ao alertar para o fato de que uma mulher - mesmo em pleno século $X X$ - poderia ser inserida em um contrato de casamento desfavorável a ela porque nem todas as mulheres tinham acesso a um conhecimento religioso-jurídico que lhes permitisse fazer alterações no contrato de casamento no sentido de fornecer garantias jurídicas de que direitos como o acesso à educação (ou seja, continuar a sua formação educacional mesmo depois de casada), a permissão para poder trabalhar (algo que por conta da jurisprudência islâmica clássica ainda depende do consentimento formal do marido), bem como o direito de divorciar-se e ter acesso ao seu patrimônio econômico.

Kecia Ali $(2003$; 2013) argumenta que a crítica feminista deve ir além da busca de informar as mulheres sobre seus direitos que podem ser assegurados quando da celebração do contrato de casamento e incorporar um questionamento do que a pesquisadora denomina de preceitos que compóem o contrato de casamento. Para Ali (2003, p. 175-179) embora a preocupação de abordagens progressistas, como a de Azizah Al-Hibri, que visam garantir a celebração de contratos de casamento mais igualitários sejam de grande mérito só seriam capazes de alcançar avanços de curto prazo nesta matéria por conta de dois fatores principais. Primeiro, a estratégia de inserir estipulações ou cláusulas no contrato de casamento não é tão direta, se tomarmos como base a jurisprudência e o segundo, que de acordo com Ali (2003) seria o mais importante é a percepção de que a inserção das cláusulas ou 
condições não altera a essência básica de desigualdades subjacentes aos direitos dos cônjuges.

\section{CONSIDERAÇÕES}

As leis de família ou códigos de status pessoal figuram ainda em pleno século XXI um campo de disputa entre os discursos que denominarei de neoconsevadores e neoreformistas (como a construção discursiva das feministas islâmicas, por exemplo), visto que as supramencionadas leis constituem um espaço em que a religião continua a exercer uma forte influência em aspectos da vida cotidiana dos muçulmanos, como na regulação do casamento, do divórcio e da custódia de filhos.

O discurso neoconservador está mais relacionado ao movimento do islã político (sobretudo nas últimas décadas do século $X X$ ) e de seu discurso rígido que sob o slogan do retorno a Shari'a trouxe para a cena política e religiosa a jurisprudência islâmica clássica (fiqh) para justificar, por exemplo, o caráter conservador com relação aos papeis de gênero na sociedade. É importante mencionar que este retorno à lei islâmica (de forma geral) foi uma espécie de ponto de inflexão com relação ao processo ocorrido ainda nas primeiras décadas do século XX que promoveu a alteração de leis e sistemas jurídicos em países do Oriente Médio e Norte da África, tendo como influência modelos idealizados e aplicados em países europeus que atuavam como entidades colonialistas na região, e como consequência culminou na restrição da religião à esfera privada.

A manutenção de uma construção clássica de gênero e, portanto da relação de interdependência dos direitos e deveres entre homens e mulheres que era característica das interpretações entendimentos das escolas de pensamento jurídico entre os séculos VII e IX, após o processo de reforma seletiva das leis, suscitou questionamentos por parte de parcela das mulheres muçulmanas ainda na primeira metade do século XX e que deu origem simultaneamente a uma plataforma para a atuação de movimentos sociais que visam a alterações no seu status nas diversas sociedades de população muçulmana e a um contra-discurso que argumentava que as aspirações femininas relacionadas à revisão e/ou ampliação dos direitos das mulheres já haviam sido contempladas 
no período de formação do Islã, argumentando que neste momento de transição a condição humana da mulher foi reconhecida.

No contexto internacional observou-se nas últimas décadas do século XX a expansão de legislação acerca dos Direitos Humanos com foco no que diz respeito aos direitos das mulheres, como foi o desenvolvimento da Comissão para Eliminação das Formas de Discriminação Contra a Mulher (Cedaw) em 1979, e alguns países muçulmanos (com populações muçulmanas minoritárias ou majoritárias) tiveram que lidar com o debate entre forças tradicionais e/ou conservadoras e as forças reformadoras e /ou críticas no interior do Islã; aspecto observado, por exemplo, com a Declaração do Cairo sobre Direitos Humanos no Islã, elaborada em 1990 pela Organização de Cooperação Islâmica (OIC) e que foi vista como uma espécie de resposta mais alinhada ao pensamento tradicional e/ou conservador religioso para argumentar pela não aplicação de certos artigos da Cedaw como, por exemplo, o artigo $16^{\circ}$ que diz respeito à adoção de medidas para eliminar a discriminação contra a mulher em todas as questões relacionadas ao casamento, seu exercício e possível dissolução, e às relações familiares, ou seja, estipulando assim a igualdade de direitos para homens e mulheres.

As medidas que constam no parágrafo primeiro do artigo 16 da Cedaw foram vistas por diversos países de população muçulmana como incompatíveis com a Shar'ia, que muitas vezes era tida como elemento inquestionável e limite máximo de todas as ações dos cidadãos que sob ela viviam, mesmo que a lei islâmica fosse fruto de entendimentos e interpretações humanas como apontam assertivamente as críticas feministas islâmicas.

O discurso neoreformista, que para os propósitos das discussões deste artigo foi analisado sob a égide da construção discursiva do feminismo islâmico (principalmente com a produção intelectual e ativista que foi desenvolvida e teve sua influência ampliada na década de 1990), enfatizando a crítica de suas expoentes acerca da tríade gênero, sexualidade e direitos das mulheres nas leis de família muçulmanas. Diferentemente do discurso do modernismo islâmico que ao argumentar pela reforma da tradição religiosa para lidar com os desafios impostos pelas sociedades modernas conferiu sustentação teórica para o processo de reformas 
das leis no início do século XX, este novo discurso reformista retomou a preocupação com o status da mulher nas diversas sociedades muçulmanas e buscou ir além da noção de equidade/complementaridade e a partir de uma interpretação independente (ijtihad) das fontes sagradas do Islã (Alcorão, ahadith, figh) reposicionando a questão dos direitos das mulheres no conflito entre uma interpretação tradicionalmente conferida aos textos religiosos (exemplificada nas diretrizes centrais das escolas de pensamento jurídico, por exemplo) e às práticas sociais que são sustentadas por tal interpretação.

O fortalecimento do discurso ativista pelo direito das mulheres em contexto muçulmano conseguiu em meio à ascensão do discurso conservador a paradoxal abertura para críticas internas com relação à jurisprudência islâmica clássica (figh) e que sustentava do ponto de vista jurídico e ideológico as leis de família e as práticas sociais a elas relacionadas, como, por exemplo, os procedimentos a serem adotados para a celebração de contratos de casamento ou para um divórcio.

A perspectiva feminista islâmica acerca das leis de família muçulmanas não se encerra nas três questões centrais mobilizadas neste artigo, sobretudo tendo em vista a complexidade do debate, mas deste exercício da crítica feminista islâmica acerca da intersecção entre gênero, sexualidade e seus reflexos nas leis de família muçulmanas três elementos devem ser ressaltados devido sua importância para discussões futuras. Primeiro, não é possível determinar de maneira categórica que uma escola de pensamento jurídico é exclusivamente liberal ou conservadora em seus posicionamentos acerca dos direitos das mulheres e dos elementos que compõem as leis de família pois em determinados aspectos uma escola pode ser mais liberal, como, por exemplo, na escola Hanafi que ao mesmo tempo em que restringe a extensão da figura do wali a um poder consultivo para que uma mulher possa celebrar um contrato de casamento, e em outros como os procedimentos para o divórcio é mais restritiva à atuação da mulher. Ou seja, a flexibilidade de uma escola de pensamento pode ser objeto de discussão interna e orientar novas interpretações de tradições já estabelecidas.

Segundo, o caráter interdependente dos direitos e deveres de homens e mulheres, expresso na interpretação clássica da passagem 
4:34 do Alcorão, por exemplo, revela um entendimento patriarcal que é usado ao mesmo tempo para legitimar o controle do corpo feminino e de sua sexualidade (tida muitas vezes como perigosa para a ordem social) e desta forma reforçar o postulado da autoridade masculina junto à família e à sociedade. E terceiro, a crítica feminista islâmica possui o potencial de alterar as relações de poder em que está inserida, questionando postulados tradicionais e desenvolvendo um projeto epistêmico que seja uma alternativa que realmente atenda aos anseios de igualdade e ampliação de direitos por parte de mulheres muçulmanas em diversos países do Oriente Médio e Norte da África.

\section{REFERÊNCIAS BIBLIOGRÁFICAS}

AHMED, Leila. Women and Gender in Islam. New Haven \& London: Yale University Press, 1992.

ALCORÃO. Alcorão - livro sagrado do Islã. Tradução Mansour Chalita. Rio de Janeiro: Bestbolso, 2015.

AL-HIBRI, Azizah. Islam, law and custom: Redefining Muslim women's rights. University of Richmond, Journal of International Law \& Policy, vol.12, n.1, 1997, p.1-44.

ALI, Kecia. Progressive Muslims and Islamic jurisprudence: the necessity for critical engagement with marriage and divorce law. In: SAFI, Omar (Org.). Progressive Muslims on Justice, Gender and Pluralism, 2003, p. 163-189.

. Marriage, family, and sexual ethics. In: RIPPIN, Andrew (Org.). The Islamic World. Routledge, 2013. p. 631-643.

AN-NA'IM, Abdullahi A. Shar'ia and Islamic Family Law: Transition and Transformation. In: Abdullahi A. An-Na'im (ed.). Islamic Family Law in a Changing World, London: Zed Books, 2002,p.1-22.

BADRAN, Margot. Feminism in Islam. Secular and Religious Convergences. $1^{\mathrm{a} e d .}$ Oxford:Oneworld Oxford, 2009, p.17-54; 215-338.

BARLAS, Asma. Muslim Women and sexual opression: reading libertation from the Quran. Macalester International, vol.10, n.15, p. 117-146, 2001.

CASTILLO, Víctor Luis Gutiérrez. The Organization of Islamic Cooperation in contemporary international society. Revista Electrónica de Estudios Internacionales (REEI), n. 27, 2014, p. 14-21.

CONVENTION ON THE ELIMINATION OF ALL FORMS OF DISCRIMINATION AGAINST WOMEN. CEDAW. Disponível em <https://treaties.un.org/doc/Publication/MTDSG/Volume\%20l/Chapter\%2olV/IV-8.en.pdf>. Acesso em: 10 mar. 2020. 
CHAUDHARY, Ayesha S. The problems of Conscience and Hermeneutics: a few contemporary approaches. Comparative Islamic Studies, vol.2, issue2, 2008, p. 157-170.

EI SAADAWI, Nawal. A face oculta de Eva: as mulheres do mundo árabe. São Paulo, Editora Global, 2002, p.23-112.

ESPOSITO, John L.; DELONG-BAS, Natana J. Women in muslim family law. New York: Syracuse University Press, 2001, p. 12-46.

ESPOSITO, John L. (Ed.). The Ofxord Dictionary of Islam. New York: Oxford University Press, 2004.

FADEL, Mohammed. Reinterpreting the Guardian's Role in the Islamic Contract of Marriage: The Case of the Maliki School. The Journal of Islamic Law, vol.3,n.1, 1998, p.1-26. ISKANDAR, Jamil Ibrahim. Al-Qur'na: O Corão, o Livro Divino dos Muçulmanos. In: PEREIRA, Rosalie Helena de Souza (Org.). O Islã Clássico: itinerários de uma cultura. São Paulo: Perspectiva, 2007, p. 97-128.

MASUD, Muhammad Khalid. Clearing Ground: Commentary to 'Shar'ia and the Modern State'. In: EMON, Anver M; ELLIS, Mark; GLAHN, Benjamin. Islamic Law and International Human Rights Law - searching for common ground?. Oxford: Oxford University Press, 2012, p. 107-114.

MIR-HOSSEINI, Ziba. The construction of gender in Islamic legal thought and strategies to reform. Hawwa: Journal of Women in the Middle East and the Islamic World, vol.1,n.1, 2003, p.1-28.

.Towards gender equality: Muslim family laws and the Shari 'ah. In: ANWAR, Zainah (Org.). Wanted: Equality and Justice in the Muslim Family,Musawah,2009, p.23-63.

. Criminalizing sexuality: zina laws as violence against women in Muslim contexts. SUR-International Journal on Human Rights., v. 15, 2011, p.7-33.

MOTAHARI, Ayatollah Mortedha. Os Direitos das Mulheres no Islam. São Paulo: Centro Islâmico do Brasil, 2008.

MUDAWANA (Código de Família Marroquino de 2004/Versão em inglês). Disponível em <http://hrea.org/programs/gender-equality-and-womens-empowerment/moudawana>. Acesso em: 01 mar. 2020.

ORGANIZATION OF ISLAMIC CONFERENCE (OIC). Cairo Declaration on Human Rights in Islam, 5 ago. 1990. Disponível em <https://www.refworld.org/docid/3ae6b3822c.html>. Acesso em: 08 mar. 2020.

RIAL, Carmen. Princesas, sufragistas, islâmicas, laicas, onguistas, escritoras- a luta feminista no Irã: entrevista com Azadeh Kian-Thiébaut. Revista Estudos Feministas, v. 16, n. 1, 2008, p. 145-169.

SHAIKH, Sa'Diuyya. Exegetical violence: Nushuz in Quranic Gender Idelogy. Journal for Islamic Studies, vol.17, 1997, p.49-73. 
WELCHMAN, Lynn. Women and Muslim family laws in Arab states: a comparative overview of textual development and advocacy. Amsterdam: Amsterdam University Press, 2007.

YAKEN, Fathi. O islam e o sexo. São Paulo: Centro de Divulgação do Islam para América Latina, 1992.

Submetido em: 11-10-2019

Aceito em: 18-4-2020 